\title{
Effects of Soil Aeration and Fertilization Practices on Alleviating Iron Deficiency Chlorosis in "Huangguan" Pears Grafted onto Quince A in Calcareous Soils
}

\author{
Yanyan Zhao ${ }^{1,2}$, Haigang $\mathrm{Li}^{1}$, Mingde Sun ${ }^{2}$, Zhenxu Liang ${ }^{2}$, Futong $\mathrm{Yu}^{3}$, Fei $\mathrm{Li}^{1, *}$ and Songzhong Liu ${ }^{2, *}$ \\ 1 Inner Mongolia Key Laboratory of Soil Quality and Nutrient Resource, College of Grassland, \\ Resources and Environment, Inner Mongolia Agricultural University, Hohhot 010018, China; \\ yanyanzhao@emails.imau.edu.cn (Y.Z.); haigangli@imau.edu.cn (H.L.) \\ 2 Key Laboratory of Biology and Genetic Improvement of Horticultural Crops (North China), \\ Ministry of Agriculture, Beijing Engineering Research Center for Deciduous Fruit Trees, Beijing Academy of \\ Forestry and Pomology Sciences, Beijing 100093, China; sunmingde@baafs.net.cn (M.S.); \\ liangzhenxu@baafs.net.cn (Z.L.) \\ 3 College of Agricultural Resources and Environmental Sciences, China Agricultural University, \\ Beijing 100193, China; futongyu@cau.edu.cn \\ * Correspondence: author: lifei@imau.edu.cn (F.L.); liusongzhong@baafs.net.cn (S.L.)
}

check for updates

Citation: Zhao, Y.; Li, H.; Sun, M.; Liang, Z.; Yu, F.; Li, F.; Liu, S. Effects of Soil Aeration and Fertilization Practices on Alleviating Iron Deficiency Chlorosis in "Huangguan" Pears Grafted onto Quince A in Calcareous Soils. Horticulturae 2021, 7, 172. https://doi.org/10.3390/ horticulturae7070172

Academic Editor: Esmaeil Fallahi

Received: 1 June 2021

Accepted: 24 June 2021

Published: 2 July 2021

Publisher's Note: MDPI stays neutral with regard to jurisdictional claims in published maps and institutional affiliations.

Copyright: (c) 2021 by the authors. Licensee MDPI, Basel, Switzerland. This article is an open access article distributed under the terms and conditions of the Creative Commons Attribution (CC BY) license (https:// creativecommons.org/licenses/by/ $4.0 /)$.

\begin{abstract}
In North China, the high-quality pear cultivar "Huangguan" (Pyrus bretschneideri Rehd. cv), which is grafted onto dwarf quince A (Cydonia oblonga Mill. cv) rootstock and grown in calcareous soil, experiences severe iron $(\mathrm{Fe})$ deficiency; this deficiency greatly constrains tree growth as well as fruit yield and quality. Therefore, we evaluated the effects of six practices for alleviating chlorosis caused by Fe deficiency in "Huangguan" grafted onto quince A (HG-QA). The practices included ridging with landscape fabric mulching as a control, flattening with landscape fabric mulching (FM), ridging without landscape fabric mulching (R), flattening without landscape fabric mulching $(\mathrm{F})$, Fe fertilizer application in soil (SFe), foliar Fe application (FFe), and manure application (M). The results showed that the leaf Fe concentration increased by $356 \%$ under FFe, compared to that under the control, but the practice failed to alleviate Fe deficiency chlorosis. In contrast, an increase in leaf Fe concentration and chlorosis alleviation were observed under F. F alleviated chlorosis mainly by increasing the root ferric-chelate reductase activity. These results indicate that Fe uptake and utilization in leaves are independent biochemical processes and soil aeration improvement have positive effect on increasing Fe uptake. M improved both the soil active Fe concentration and leaf Fe utilization. Thus, manure application should be the first choice for alleviating Fe deficiency chlorosis in HG-QA grown in calcareous soils. Combining manure application with other practices that increase Fe uptake would likely be an effective way to address the problem of Fe deficiency chlorosis.
\end{abstract}

Keywords: pears; Fe deficiency; fertilization; chlorosis alleviation; calcareous soil

\section{Introduction}

Iron $(\mathrm{Fe})$ is a necessary micronutrient for plant growth and development and plays an important role in intracellular metabolism [1,2], such as electron transfer and is required for many enzymes to complete biological functions. Fe deficiency chlorosis is a worldwide nutritional disorder in crop plants as well as fruit trees. It reduces or even arrests the growth of fruit trees and consequently decreases fruit yield and quality.

Fe deficiency chlorosis often occurs when plants grow in calcareous soils, even though the total Fe concentration in such soils is high [3]. A previous study showed that this occurred due to the high $\mathrm{pH}$ and high bicarbonate concentration in the soil, which reduced Fe acquisition in plants by decreasing Fe bioavailability in soil and inducing Fe precipitation in the apoplast of root cells, respectively [4,5]. Moreover, inactive Fe tends to accumulate in chlorotic leaves in calcareous soils [6-8]. This indicates that Fe precipitation also occurs 
in the leaf veins and apoplast as a result of high apoplast $\mathrm{pH}$ or low leaf ferric-chelate reductase (FCR) activity [9].

China has been the world's largest pear producer since 1977 [10]. Dwarf culture is a new and highly efficient intensive cultivation mode used in pear production because of its high yields, labor savings, and simple management practices, and it is being widely adopted in the EU and USA [11]. However, quince, one of the popular dwarf rootstocks, has low Fe utilization efficiency, which often leads to Fe deficiency in the grafted pear trees [12]. In North China, pears grafted onto quince show severe interveinal chlorosis in younger leaves when grown in calcareous soil, which greatly restricts the expansion of dwarf pear culture in this region.

To alleviate Fe deficiency chlorosis in fruit trees, several direct Fe replenishment strategies have been developed, such as fertilizer application to soil $[13,14]$ and foliar spraying [15]. However, the efficiency of these strategies is variable and depends on the experimental conditions and plant species [15-17]. Foliar sprays of $\mathrm{Fe}(\mathrm{III})-\mathrm{DTPA}$ and $\mathrm{FeSO}_{4}$ temporarily increase the Fe level in pear leaves [18]. The application of Fe-EDDHA chelate increases Fe uptake by roots and its distribution to leaves in lemon trees and alleviates the chlorosis [13]. Moreover, these chelates are expensive and inevitably increase production costs [18].

Many studies have also shown that some practices can indirectly promote Fe uptake by plants $[19,20]$. Conventional tillage (soil plowing at $20 \mathrm{~cm}$ ) significantly increases $\mathrm{Fe}$ accumulation in peanuts by $51.2 \%$ compared with that under no tillage [21]. Short, highfrequency irrigation periods alleviate leaf chlorosis in apple and pear trees in calcareous soils with a caliche layer [22]. Ridging with mulching is a routine practice in fruit cultivation $[20,23,24]$. It is presumed possible to change soil Fe bioavailability by modifying soil aeration. Farmers often apply manure to build soil fertility in fruit orchards. Application of manure changes most issues such as texture, microorganisms, and organic matter content that effects Fe uptakes. Meanwhile, many micronutrients contained in the manure, including $\mathrm{Fe}$, are input into the soil at the same time. In some studies, the soil bioavailable Fe content and the Fe concentration in pear leaves increased after manure application $[19,25]$. These low-cost practices may be optimal ways to alleviate chlorosis in fruit trees grown in calcareous soils.

In this study, we compared the effects of six practices on alleviating Fe deficiency chlorosis in pear, including flattening with mulching, ridging without mulching, flattening without mulching, Fe fertilizer application in soil, foliar Fe application, and manure application (ridging with mulching was used as a control), with the goal of identifying a low-cost, high-efficiency practice for dwarf pear cultivation in North China.

\section{Materials and Methods}

\subsection{Plant Materials and Experimental Conditions}

This study was conducted in Beijing, North China $\left(40^{\circ} 11^{\prime} 7.00^{\prime \prime} \mathrm{N}, 116^{\circ} 29^{\prime} 42.17^{\prime \prime} \mathrm{E}\right)$, at an altitude of $40 \mathrm{~m}$ above sea level. This area experiences a continental monsoon climate. The annual precipitation and average temperature are $550 \mathrm{~mm}$ and $10{ }^{\circ} \mathrm{C}$, respectively. Most of the annual precipitation occurs during a few large rainfall events from July to September. The soil in the experimental orchard was a silt loam with clay, silt, and sand proportions of $5.40 \%, 64.7 \%$, and $29.9 \%$, respectively.

Three-year-old trees of the pear cultivar "Huangguan" (Pyrus bretschneideri Rehd. cv) grafted onto quince A (Cydonia oblonga Mill. cv) with Hardy as the interstock (abbreviated as HG-QA) were used in this study. The trees were trimmed to slender spindles and grown at high density (spacing of $1.0 \mathrm{~m}$ within rows and $3.5 \mathrm{~m}$ between rows, 2857 trees ha $^{-1}$ ). To ensure high quality and quantity in the pears, ridging with landscape fabric mulching was implemented throughout the whole orchard before the treatments were established. The ridges along the tree rows were $30 \mathrm{~cm}$ high and $140 \mathrm{~cm}$ wide. Under these conditions, HG-QA leaves exhibited obvious interveinal chlorosis (Figure 1A). A foliar Fe fertilizer was 
sprayed onto the chlorotic leaves, and the leaves turned partially green, which confirmed that the chlorosis in these leaves was caused by Fe deficiency (Figure 1B).
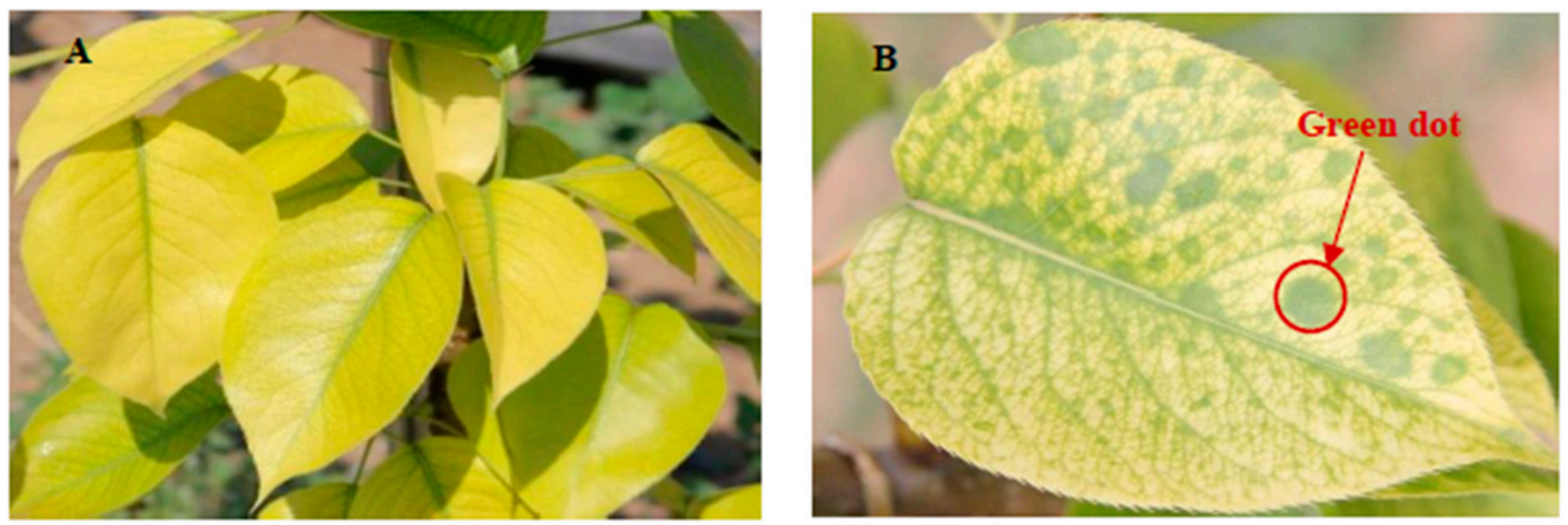

Figure 1. Leaves' color of "Huangguan" pear grafted onto quince A grown in pear research base of Beijing with calcareous soil (A) and the green dots in pear leaves caused by a foliar Fe application (B).

\subsection{Experimental Implementation}

Seven experimental practices were implemented in mid-April 2019 (Figure 2): (1) ridging with landscape fabric mulching (control), (2) flattening with landscape fabric mulching (FM), (3) ridging without landscape fabric mulching (R), (4) flattening without landscape fabric mulching (F), (5) manure applied to the control conditions (M), (6) soil Fe fertilizer applied to the control conditions (SFe), and (7) foliar Fe applied to the control conditions (FFe). The manure and Fe fertilizer application practices were as follows: for the $\mathrm{M}$ treatment, two ditches ( $40 \mathrm{~cm}$ deep, $40 \mathrm{~cm}$ long, and $30 \mathrm{~cm}$ wide) along the rows on both sides of trees (30 $\mathrm{cm}$ away from the tree) were dug, and then sheep manure $(0.01 \% \mathrm{Fe}, 40 \%$ organic carbon, $\mathrm{pH}$ 8.14) mixed with soil (sheep manure-soil ratio of 1:3) was placed into each ditch; for the SFe treatment, two ditches $(10 \mathrm{~cm}$ deep, $40 \mathrm{~cm}$ long, and $30 \mathrm{~cm}$ wide) were dug in the same location as described previously, and $1.0 \mathrm{~g}$ Fe as polysaccharide chelate $\mathrm{Fe}$ solution ( $\mathrm{pH}$ 5.5, $0.5 \mathrm{~g} \mathrm{Fe} \mathrm{L}^{-1}$ ) was poured into each ditch every fifteen days; for the FFe treatment, $25 \mathrm{mg} \mathrm{Fe} \mathrm{L}^{-1}$ mannitol chelate Fe was sprayed on both sides of the leaves every ten days.

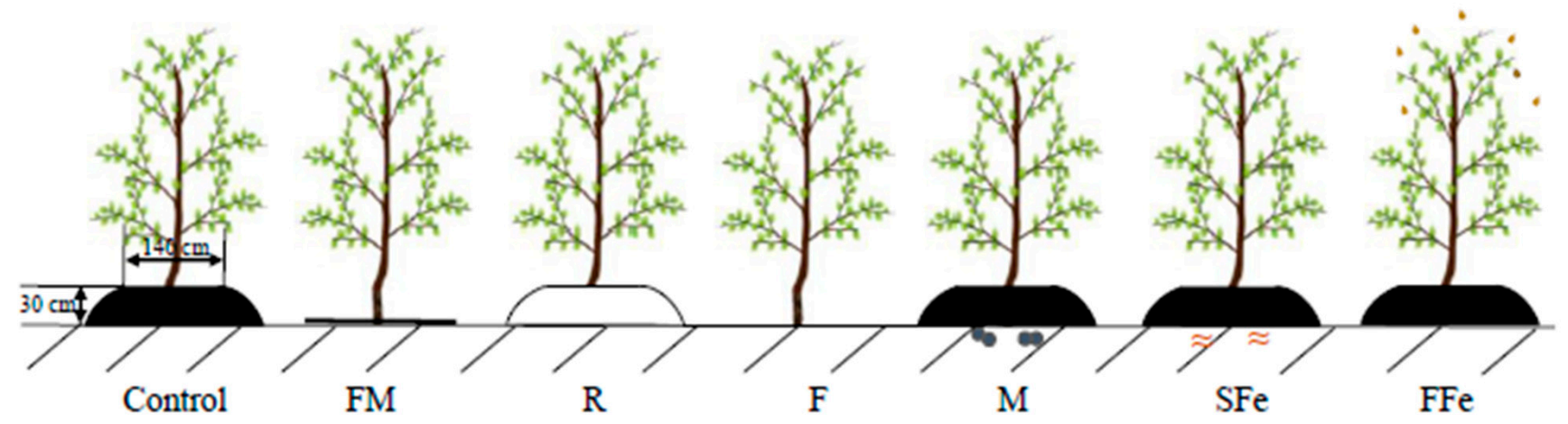

Figure 2. Schematic diagram of the practices. Control: ridging with landscape fabric mulching and without other treatments; FM: flattening with landscape fabric mulching, R: ridging without landscape fabric mulching; F: flattening without landscape fabric mulching; M: Manure application; SFe: Fe application in soil; FFe: Foliar Fe application.

There were 5 replicates of each practice, with 1 tree per replicate. In mid-July, soil and plant samples were collected. 


\subsection{Leaf Soil Plant Analysis Development (SPAD) Value}

A SPAD-502 (Minolta, Osaka, Japan) was used to determine the SPAD of fully expanded leaves (the fourth leaves from the tips of the new shoots). Then, the measured leaves were harvested and used for the Fe concentration determination.

\subsection{Rhizosphere pH, Soil Active Fe Concentration, and Soil Moisture}

A gasoline-powered soil sampler was used to sample soils near the root zone (unfertilized area) at a depth of $0-40 \mathrm{~cm}$. After removing the loosely adhering soil around the roots, the tightly adhering soils were collected as the rhizosphere soil. Aliquots of rhizosphere soil were used for $\mathrm{pH}$ measurements (water:soil ratio of 1:1) with a $\mathrm{pH}$ meter (FE20K PLUS PH, Mettler-Toledo, Switzerland). Soil active Fe measurements were performed by extraction with DTPA and determination by plasma emission spectrometry (ICP-OES, OPTIMA 3300 DV, Perkins-Elmer Inc., Waltham, Massachusetts, USA) at $248.3 \mathrm{~nm}$ band and with the error not to exceed $1 \%$ deflection on the absorbance scale [26]. The rest of the soil in each sample was weighed immediately and then dried to a constant weight.

$$
\text { Soil moisture }(\%)=(\text { fresh weight }- \text { dry weight }) / \text { dry weight } \times 100 \%
$$

\subsection{Root FCR Activity}

Fresh root samples were used to determine the FCR activity according to the modified procedure of Zheng et al. [27]. The capillary roots were gently cut off and immediately washed with deionized water and dipped in the reaction solution $\left(0.5 \mathrm{mM} \mathrm{CaSO}_{4}, 0.1 \mathrm{mM}\right.$ MES, $0.1 \mathrm{mM}$ BPDS, $100 \mu \mathrm{M}$ Fe(III)-EDTA; $\mathrm{pH}$ 5.5) for $30 \mathrm{~min}$. A rootless reaction solution was run simultaneously as the blank control. The absorbance of the Fe(II)-BPDS complex was measured at $535 \mathrm{~nm}$ with a UV-Vis spectrophotometer (UV1900PC). A standard curve was used to calculate the activity of root FCR.

\subsection{Leaf Fe Concentration}

The leaves harvested from the trees were washed three times with deionized water and then dried in a forced-draft oven at $105^{\circ} \mathrm{C}$ for the first $2 \mathrm{~h}$ and then to constant weight at $85^{\circ} \mathrm{C}$. The dried samples were ground into powder and digested at $220^{\circ} \mathrm{C}$ for $30 \mathrm{~min}$ in the presence of $13 \mathrm{M} \mathrm{HNO}_{3}$ and $8.8 \mathrm{M} \mathrm{H}_{2} \mathrm{O}_{2}$. The Fe concentrations of the leaves were measured with a plasma emission spectrometer (ICP-OES, OPTIMA 3300 DV, PerkinsElmer Inc., Waltham, Massachusetts, USA) at $248.3 \mathrm{~nm}$ band and with the error not to exceed $1 \%$ deflection on the absorbance scale [26].

\subsection{Statistical Data Analysis}

The experiments were set up in a completely randomized design with 5 replicates. The factor levels are control, FM, R, F, M, SFe, and FFe. Data were obtained from soil (active Fe concentration and soil moisture), leaves (SPAD, leaf Fe concentration and the ratio of SPAD to the leaf Fe concentration), and roots (root FCR activity and rhizosphere $\mathrm{pH}$ ). Three independent one-way MANOVA (multivariate analysis of ANOVA) models were used in the data, one for "soil" variables, one for "root" variables and one for "leaf" variables.

Before analysis, Shapiro-Wilk test and Levene's test were used to check the hypothesis of the normality of the residuals and variance homogeneity along the factor levels, respectively. The Shapiro-Wilk test showed that the residuals were normally distributed $(p>0.05)$. The Levene's test showed that the variances of active Fe concentration, soil moisture, the ratio of SPAD to the leaf Fe concentration and rhizosphere $\mathrm{pH}$ were all homogeneous $(p>0.05)$, and the variances of SPAD, leaf Fe concentration and root FCR activity were heterogeneous $(p \leq 0.05)$. Tukey's test $(p<0.05)$ was used as a post hoc test method to calculate the significant differences among treatment means with the SPSS 20.0 program (Inc., Chicago, IL, USA) when variances were homogeneous, and Games-Howell test $(p<0.05)$ was used when variances were heterogeneous. Finally, Benjamini-Hochberg false 
discovery rate (FDR) method was used to correct for multiple testing, and the FDR $p$ value was considered statistically significant only if it was less than 0.05 .

\section{Results}

\subsection{Leaf SPAD Values}

The analysis results showed that the differences of "leaf" variables under different treatments were statistically significant (Wilks' Lambda $=0.002, \mathrm{~F}=30.689, p<0.001$ ). The results of between-subjects effects showed that the differences of SPAD among different treatments were statistically significant $(p<0.001)$.

The leaf SPAD values and post hoc test results are shown in Figure 3. The leaf SPAD values ranged from 11.7 to 29.7 among the different treatments. The leaf SPAD values under $\mathrm{F}$ and $\mathrm{M}$ were $167 \%$ and $165 \%$ higher than that under the control, respectively. The lowest SPAD value under $\mathrm{R}$ was 11.7 , which was only $65.7 \%$ of that under the control. The leaf SPAD values under FM and FFe were the same as that under the control.

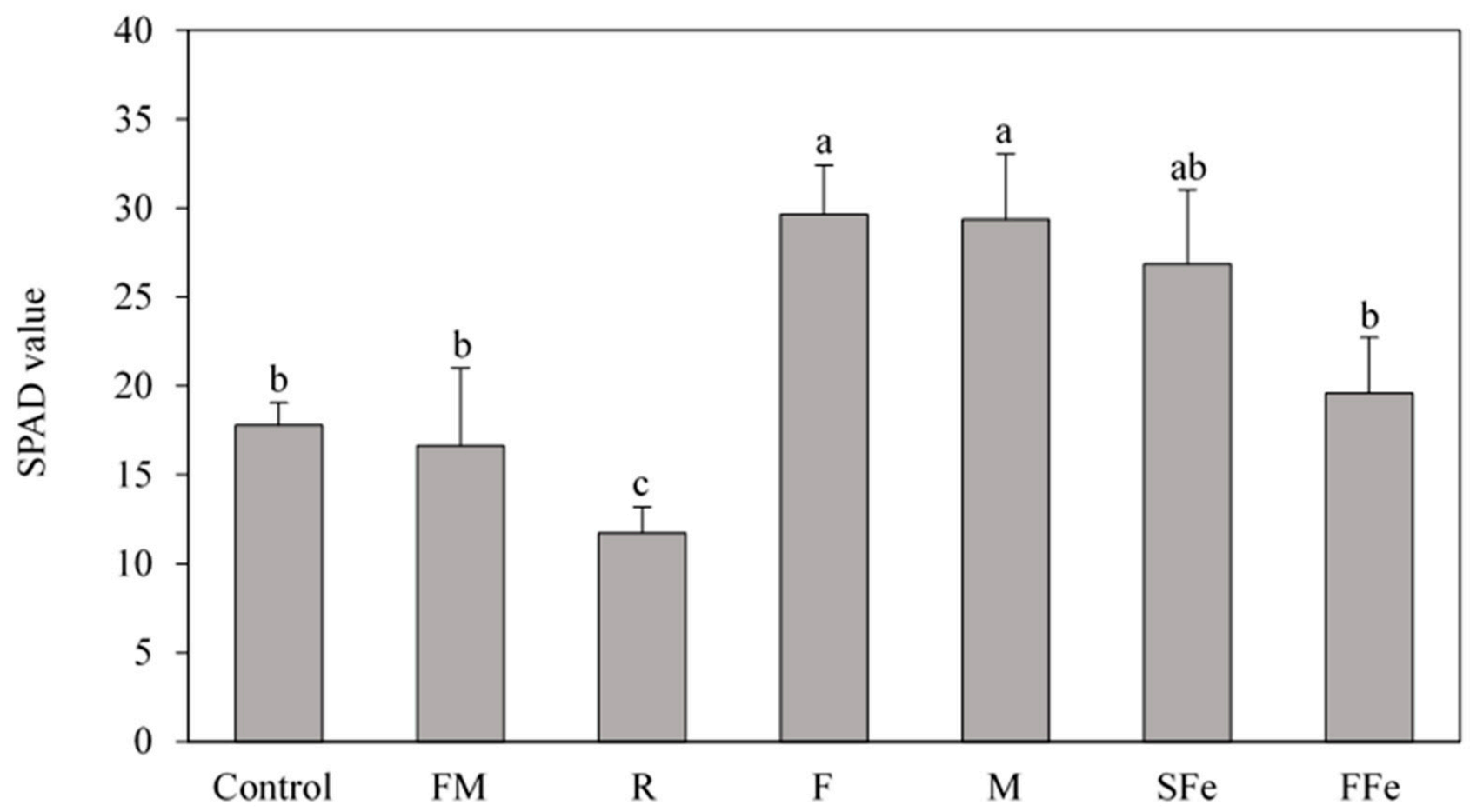

Figure 3. The soil plant analysis development (SPAD) values of HG-QA leaves grown in different practices. HG-QA: "Huangguan" pear grafted onto quince A. Control: ridging with landscape fabric mulching and without other treatments; FM: flattening with landscape fabric mulching, R: ridging without landscape fabric mulching; F: flattening without landscape fabric mulching; M: Manure application; SFe: Fe application in soil; FFe: Foliar Fe application. The different letters mean statistical differences between treatments, $p<0.05$ (Benjamini-Hochberg correction).

\subsection{Soil Active Fe Concentrations and Soil Moisture}

The analysis results showed that the differences of "soil" variables under different treatments were statistically significant (Wilks' Lambda $=0.013, \mathrm{~F}=34.305, p<0.001$ ). The results of between-subjects effects showed that the differences of soil active Fe concentrations and soil moisture among different treatments were statistically significant $(p<0.001)$.

The soil active Fe concentrations and post hoc test results are shown in Figure 4A. The soil active Fe concentrations were similar among the FM, R, F, and FFe treatments and the control at approximately $8.00 \mathrm{mg} \mathrm{kg}^{-1}$. The soil active Fe concentrations under $\mathrm{M}$ and SFe were $11.31 \mathrm{mg} \mathrm{kg}^{-1}$ and $13.39 \mathrm{mg} \mathrm{kg}^{-1}$, respectively; they were not significantly different from each other but were significantly higher than those under FM and the control. 

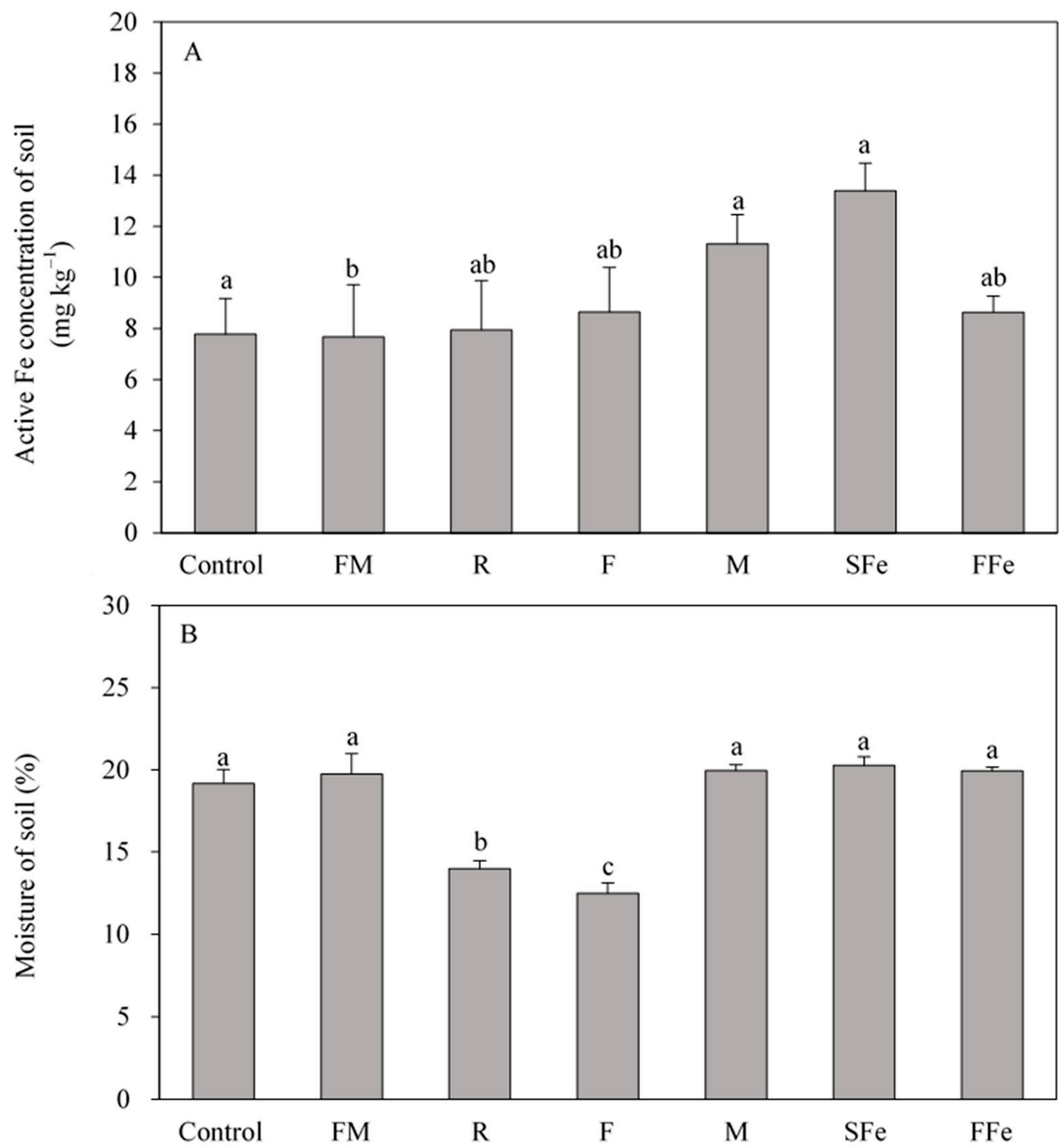

Figure 4. Active Fe concentration (A) and moisture of soil (B) in 0-40 cm depth of HG-QA grown in different practices. HG-QA: "Huangguan" pear grafted onto quince A. Control: ridging with landscape fabric mulching and without other treatments; FM: flattening with landscape fabric mulching, R: ridging without landscape fabric mulching; F: flattening without landscape fabric mulching; M: Manure application; SFe: Fe application in soil; FFe: Foliar Fe application. The different letters mean statistical differences between treatments, $p<0.05$ (Benjamini-Hochberg correction).

The soil moisture data and post hoc test results are shown in Figure 4B. The soil moisture levels under $\mathrm{R}$ and $\mathrm{F}$ were $14.0 \%$ and $13.5 \%$, respectively, which were significantly lower than that under the control (19.1\%). The lowest soil moisture level was observed under F. The soil moisture levels under FM, M, SFe, and FFe were the same as that under the control and ranged from 19.73 to $20.29 \%$. 


\subsection{Root FCR Activities and Rhizosphere $\mathrm{pH}$}

The analysis results showed that the differences of "root" variables under different treatments were statistically significant (Wilks' Lambda $=0.189, \mathrm{~F}=5.858, p<0.001$ ). The results of between-subjects effects showed that the differences of root FCR activity among different treatments were statistically significant $(p<0.001)$ and as well as the rhizosphere $\mathrm{pH}(p=0.001)$.

The root FCR activities and post hoc test results are shown in Figure 5A. The root FCR activity under $\mathrm{F}$ was $0.31 \mathrm{Fe} \mu \mathrm{g} \mathrm{min}^{-1} \mathrm{~g}^{-1} \mathrm{FW}$, which was much higher than those under R, M, SFe, and the control (by 163-207\%). No significant difference in root FCR activity was found among $\mathrm{R}, \mathrm{SFe}$, and the control. The root FCR activity under $\mathrm{M}$ was $0.15 \mathrm{Fe} \mu \mathrm{g} \mathrm{min}^{-1} \mathrm{~g}^{-1} \mathrm{FW}$, which was significantly lower than those under $\mathrm{F}$ and FM but not significantly different from that under the control. The root FCR activity under FM

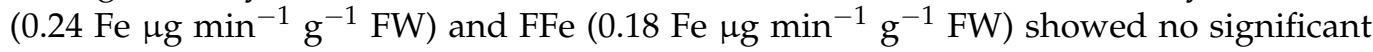
differences to that under the control.
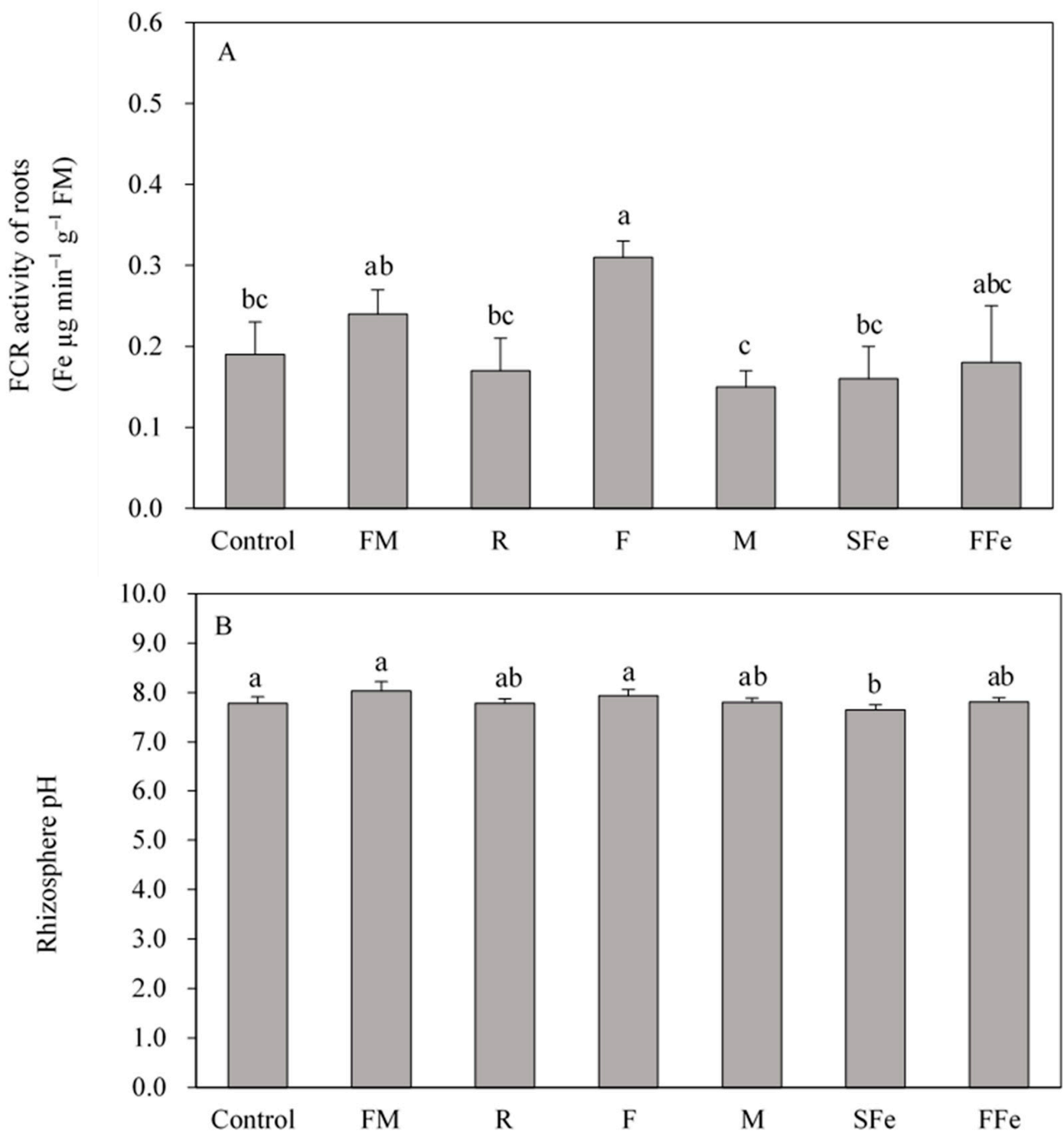

Figure 5. Ferric-chelate reductase (FCR) activity of roots (A) and rhizosphere $\mathrm{pH}(\mathbf{B})$ of HG-QA grown in different practices. HG-QA: "Huangguan" pear grafted onto quince A. Control: ridging with landscape fabric mulching and without other treatments; FM: flattening with landscape fabric mulching, R: ridging without landscape fabric mulching; F: flattening without landscape fabric mulching; M: Manure application; SFe: Fe application in soil; FFe: Foliar Fe application. The different letters mean statistical differences between treatments, $p<0.05$ (Benjamini-Hochberg correction). 
The rhizosphere $\mathrm{pH}$ data and post hoc test results are shown in Figure 5B. The rhizosphere $\mathrm{pH}$ under $\mathrm{SFe}$ was 7.65 , which was approximately 0.30 units lower than those under FM and F. The rhizosphere $\mathrm{pH}$ values under the FM, F, SFe, M, FFe, and control treatments ranged from 7.78 to 8.03 but were not significantly different from each other.

\subsection{Leaf Fe Concentrations and the Ratio of SPAD to the Leaf Fe Concentration (RSFe)}

The results of between-subjects effects showed that the differences of leaf Fe concentrations and RSFe among different treatments were statistically significant $(p<0.001)$.

The leaf Fe concentrations and post hoc test results are shown in Figure 6A. The leaf Fe concentrations under $\mathrm{F}$ and SFe were similar and were more than 1.2-fold higher than those under FM (129.2 $\left.\mathrm{mg} \mathrm{kg}^{-1}\right), \mathrm{M}\left(124.5 \mathrm{mg} \mathrm{kg}^{-1}\right)$ and the control $\left(100.4 \mathrm{mg} \mathrm{kg}^{-1}\right)$. The leaf Fe concentrations under the FM, R, M, and SFe treatments were not significantly different from that under the control. In addition, the leaf Fe concentration under FFe was $357.2 \mathrm{mg} \mathrm{kg}^{-1}$, which was nearly 2-fold higher than those under FM, R, F, M, and SFe, and 3 -fold higher than that under the control.
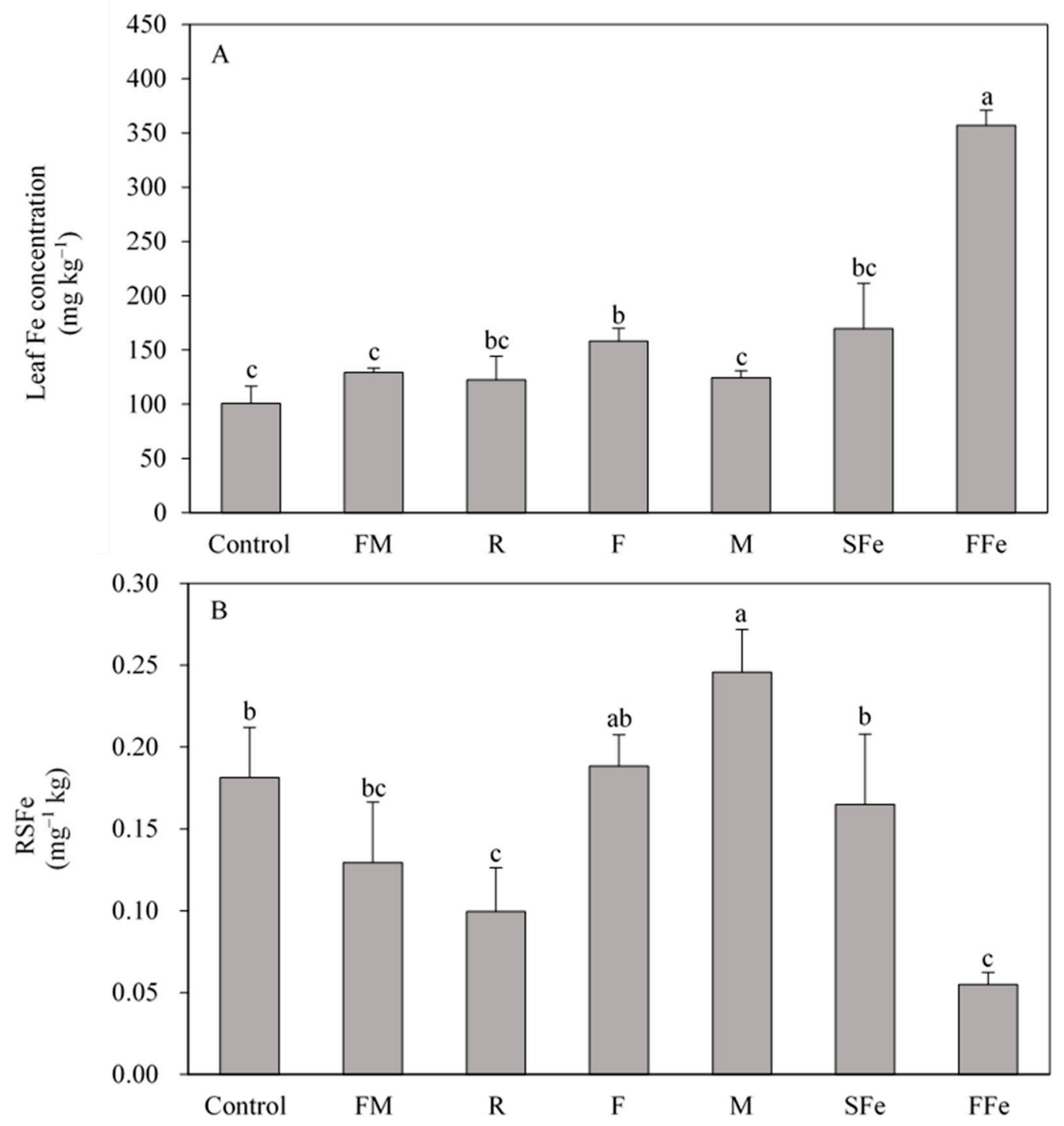

Figure 6. Leaf Fe concentration (A) and RSFe (B) of HG-QA grown in different practices. RSFe: the ratio of SPAD to the leaf Fe concentration. HG-QA: “Huangguan” pear grafted onto quince A. Control: ridging with landscape fabric mulching and without other treatments; FM: flattening with landscape fabric mulching, R: ridging without landscape fabric mulching; F: flattening without landscape fabric mulching; M: Manure application; SFe: Fe application in soil; FFe: Foliar Fe application. The different letters mean statistical differences between treatments, $p<0.05$ (Benjamini-Hochberg correction). 
The values and post hoc test results of RSFe are shown in Figure 6B. The RSFe values under $\mathrm{R}\left(0.099 \mathrm{mg}^{-1} \mathrm{~kg}\right)$ and FFe $\left(0.0549 \mathrm{mg}^{-1} \mathrm{~kg}\right)$ were significantly lower than that under the control $\left(0.181 \mathrm{mg}^{-1} \mathrm{~kg}\right)$, while the RSFe values under F, FM, SFe, and the control were not significantly different. However, the RSFe under the M group $\left(0.236 \mathrm{mg}^{-1} \mathrm{~kg}\right)$ was 1.3-fold higher than that under the control group.

\section{Discussion}

Many practices can increase the Fe concentration of leaves by directly providing Fe through fertilization, increasing the Fe absorption ability of roots or mobilizing Fe in leaves $[18,19,25]$. We tested six practices and found that only $\mathrm{F}$ and FFe increased the Fe concentration of pear leaves (Figure 6A). Leaf chlorosis was alleviated by only some of the tested practices, including F and M (Figure 3). We provide further discussion of these results below.

\subsection{Improving the Leaf Fe Concentration}

The low concentration of soil active Fe is the factor that most limits root Fe absorption in strategy I plant species grown in calcareous soils [28]. Soil organic matter is an important source of chelates and other soluble organic complexes and therefore helps to dissolve and mobilize Fe [29]. Manure application replenishes Fe-mobilizing chelates/complexes in soils [30,31] and thereby increases the concentration of soil active Fe (Figure 4A). However, high leaf Fe concentrations were not observed under the $M$ treatment, indicating that the iron absorption process was not improved. Low soil $\mathrm{pH}$ facilitates Fe(III) reduction to Fe(II) in soil solution, and Fe(II) can be absorbed by roots directly [7,32]. Fe-deficient plants often acidify the rhizosphere to enhance Fe(III) reduction [33]. However, rhizosphere acidification was observed only under the SFe treatment; leaves under this treatment also exhibited the mildest chlorosis. The active substances such as amino acids in SFe fertilizer can increase root activity [34], which further enhances proton secretion. Thus, the active adaptation of pear trees to Fe deficiency was not the only reason for the observed rhizosphere acidification; the application of acidic fertilizer in SFe also decreased the soil $\mathrm{pH}$, which will contribute to chlorosis alleviation. These evens should be a concern, even though the chlorosis alleviation effect was not significant.

In addition to rhizosphere acidification, an increase in root FCR activity is another strategy for enhancing Fe(III) reduction in the rhizosphere of Fe-deficient plants [35-38]. Root FCR activity in strategy I plants was significantly inhibited by a high bicarbonate concentration in soil, which was attributed to the high soil moisture in calcareous soils [39-41], and these conditions caused Fe accumulation in the root apoplast $[5,42,43]$. Maintaining soil moisture at an optimal level decreases the soil bicarbonate concentration by increasing gas exchange in rhizosphere soil $[44,45]$, which eliminates the inhibition of root FCR activity by high bicarbonate concentrations. Under the F treatment, soil evaporation was assumed to be higher than that under other practices without ridges and film mulching, and the higher soil evaporation resulted in lower soil moisture. High root FCR activity was responsible for the high leaf Fe concentration under this treatment. However, confusing results were observed under the FM and R treatments, possibly because the impact of the individual treatment on the interaction of soil moisture and root FCR activity was not as easy to detect as the impact of both treatments combined.

\subsection{Fe Activation in Leaves}

An "Fe chlorosis paradox", in which the Fe concentration in Fe-deficient leaves is similar to or even higher than that in Fe-sufficient leaves, often occurs in the field [46,47]. Not all Fe in leaves is involved in biological processes because a large amount of Fe in leaves deposits into apoplasts as inactive Fe. The higher proportion of inactive Fe in chlorotic leaves than in non-chlorotic leaves causes this paradox [48]. Thus, activating leaf Fe is an effective strategy for alleviating chlorosis in calcareous soils [7,9]. 
The high Fe concentrations in the HG-QA leaves under the F treatment successfully alleviated the chlorosis, indicating that the Fe absorbed into leaves was not deposited in the apoplasts as inactive Fe in these trees. However, more Fe were inactivated in leaves under R treatment (Figure 6B). High bicarbonate concentrations are proposed to be a main reason for Fe inactivation in leaf apoplasts $[4,9,49]$. Under ridging and mulching practices, the bicarbonate concentration is promoted by the high levels of soil moisture incorporated with the carbonate supply in calcareous soil [44]. This is likely the reason of the inhibition of leaf Fe activation occurred under $\mathrm{R}$ than under $\mathrm{F}$.

In previous studies, foliar Fe spraying increased leaf chlorophyll content $[15,18,50]$. However, we did not find any significant improvement in the SPAD values (Figure 3) of HG-QA under FFe, although the leaf Fe concentration was 3.56-fold smaller than the control. This result indicated that the Fe added to the leaves by spraying may have been deposited in the apoplast as inactive Fe. However, recently, the addition of fullerenol to $\mathrm{Fe}(\mathrm{II})$-sulfate sprays has been shown to increase leaf active Fe and successfully suppress Fe deficiency symptoms by increasing the stability of the applied Fe(II) [51]; increasing Fe(II) stability is important for enhancing the potential of foliar Fe fertilization.

Manure application not only increased soil Fe bioavailability, but also activated Fe in the leaves of HG-QA (Figure 6B). However, the mechanism of Fe activation in leaves under manure application is still not clear. Fe inactivation in leaves in calcareous soils is probably related to the high $\mathrm{pH}$ of the leaf apoplast. Manure application may have acidified the apoplast and thus led to Fe activation.

After combining our data and analyses, we proposed a model illustrating how the different practices alleviated Fe deficiency in HG-QA grown in calcareous soils (Figure 7). The practices of $\mathrm{F}$ and FFe both increased the leaf Fe concentration. However, Fe chlorosis was alleviated only under the F and $\mathrm{M}$ treatments. More of the Fe in the apoplast may have been inactivated under $\mathrm{R}$ and FFe than under the other treatments, which would have resulted in the continuation of leaf chlorosis. The increase in root FCR activity under F and in soil active Fe under SFe and the activation of leaf Fe under $\mathrm{M}$ all contributed to alleviating leaf chlorosis. However, ridging with mulching is considered to be an effective and adaptable field management method to improve productivity in fruit cultivation $[20,23,24,52]$, which restricts the feasibility of $\mathrm{F}$ for alleviating Fe deficiency. However, it reminds us of the importance of soil aeration management on improving Fe nutrition. In addition, manure application can improve leaf Fe utilization and reduce the cost of pear production because it is less expensive than other Fe fertilizers. Therefore, manure is more appropriate for combating Fe deficiency in HG-QA trees grown in calcareous soil. However, manure can only alleviate Fe deficiency in HG-QA trees and does not provide a complete solution. Measures that can address the fundamental reasons for Fe deficiency chlorosis in HG-QA trees grown in calcareous soil need to be explored further. 


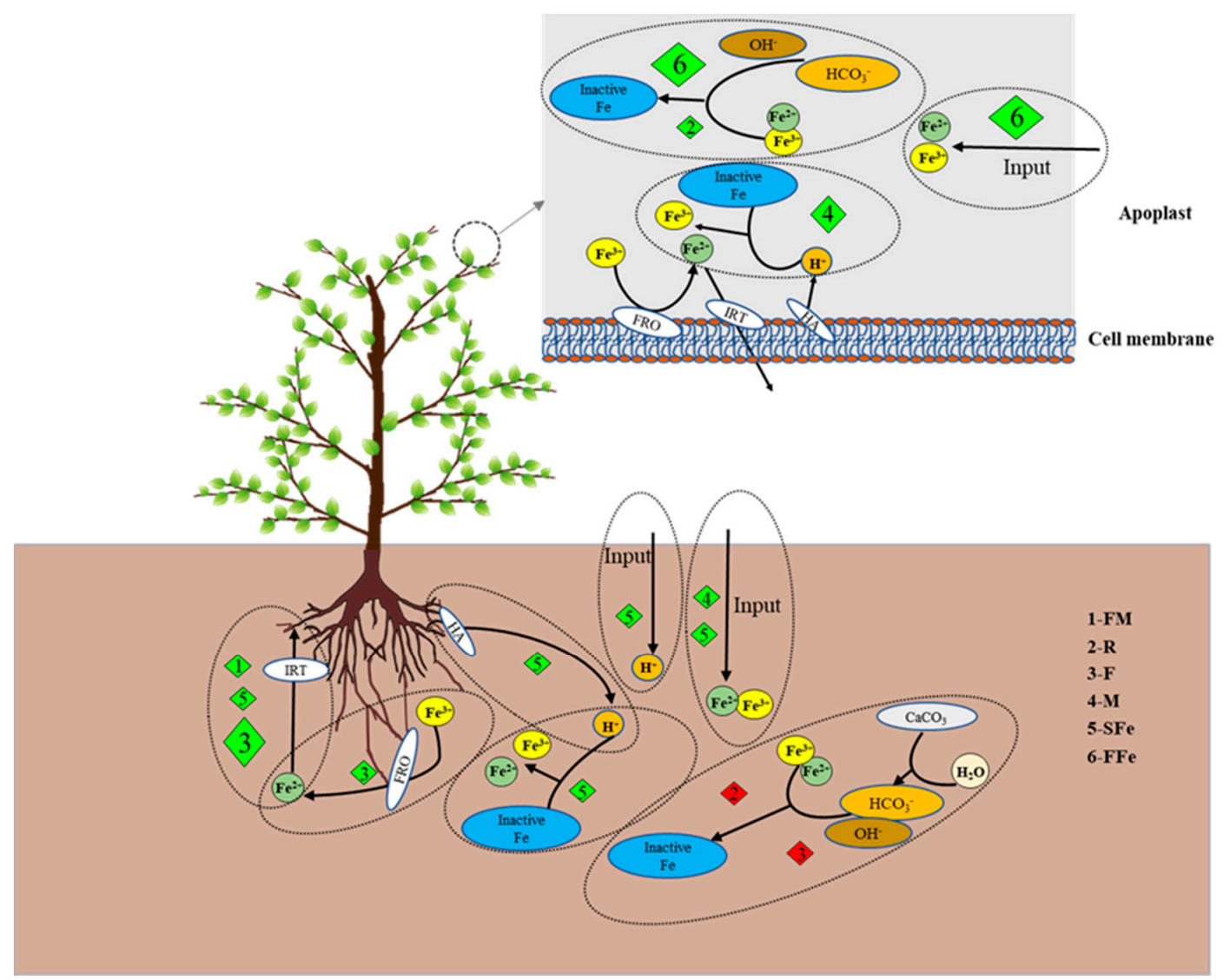

Figure 7. Model of how different practices alleviate Fe deficiency in pear trees in calcareous soil. The black arrow represents the direction of the process. The steps inside the dotted ovals represent a complete process. The diamonds with different numbers represent the different practices. The practices shown within a dotted oval will affect the corresponding process. The size of the diamond represents the magnitude of the impact of the corresponding practice. Green diamonds represent positive effects, and red diamonds represent negative effects. FM: flattening with landscape fabric mulching, R: ridging without landscape fabric mulching; F: flattening without landscape fabric mulching; M: Manure application; SFe: Fe application in soil; FFe: Foliar Fe application.

\section{Conclusions}

Practice F aimed at improving soil aeration, and it increased the Fe concentration in HG-QA leaves by decreasing soil moisture, indicating the importance of soil aeration improvement. The application of Fe fertilizers did not increase, and could even decrease, Fe utilization in leaves. This result indicated that Fe uptake and utilization in leaves were independent biochemical processes. However, only manure application had positive effects on both soil Fe increase and leaf Fe utilization even though the leaf Fe concentration was not increased. This may have been due to chelate exudation to mobilize soil Fe and the acidification of the leaf apoplast to activate leaf Fe. Thus, manure application was the first choice for alleviating Fe deficiency chlorosis in HG-QA trees grown in calcareous soils. Combining various practices that increase Fe uptake is likely to achieve greater success in addressing this problem.

Author Contributions: Conceptualization, H.L.; Data curation, Y.Z.; Formal analysis, Z.L. and F.L.; Funding acquisition, S.L.; Investigation, Y.Z. and M.S.; Methodology, H.L.; Project administration, M.S.; Resources, S.L.; Supervision, F.Y. and F.L.; Validation, Z.L.; Visualization, S.L. and F.L.; Writingoriginal draft, Y.Z.; Writing-review and editing, H.L. and F.Y. All authors have read and agreed to the published version of the manuscript. 
Funding: This study was funded by Science and Technology Innovation Capacity Building Program of Beijing Academy of Agriculture and Forestry Sciences (KJCX20200114 and KJCX20200602), and National Key R\&D Program of China (2020YFD1000202).

Institutional Review Board Statement: Not applicable.

Informed Consent Statement: Not applicable.

Data Availability Statement: Raw data are available on request.

Conflicts of Interest: The authors declare no conflict of interest.

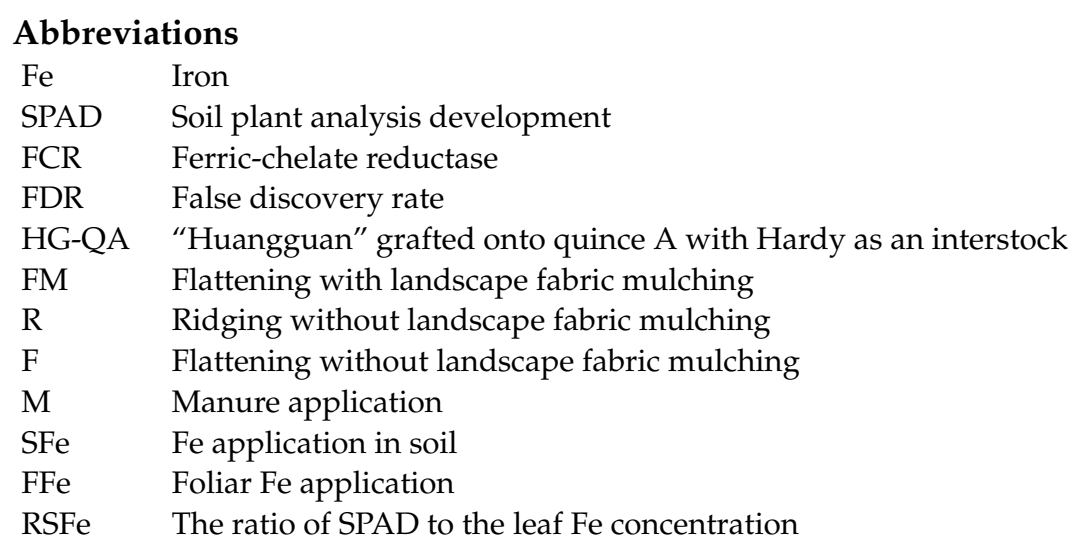

\section{References}

1. Briat, J.F.; Dubos, C.; Gaymard, F. Iron nutrition, biomass production, and plant product quality. Trends Plant Sci. 2015, 20 , 33-40. [CrossRef]

2. Thomine, S.; Vert, G. Iron transport in plants: Better be safe than sorry. Curr. Opin. Plant Biol. 2013, 16, 322-327. [CrossRef] [PubMed]

3. Bavaresco, L.; Giachino, E.; Pezzutto, S. Grapevine rootstock effects on lime-induced chlorosis, nutrient uptake, and source-sink relationships. J. Plant Nutr. 2003, 7, 1451-1465. [CrossRef]

4. Mengel, K.; Planker, R.; Hoffmann, B. Relationship between leaf apoplast $\mathrm{pH}$ and iron chlorosis of sunflower (Helianthus annuus L.). J. Plant Nutr. 1994, 17, 1053-1065. [CrossRef]

5. Zribi, K.; Gharsalli, M. Effect of bicarbonate on growth and iron nutrition of pea. J. Plant Nutr. 2002, 25, 2143-2149. [CrossRef]

6. Kosegarten, H.; Englisch, G. Effect of various nitrogen forms on the $\mathrm{pH}$ in leaf apoplast and iron chlorosis of Glycine max L. Z. Planzenernaehr. Bodenk. 1994, 157, 401-405. [CrossRef]

7. Mengel, K. Iron availability in plant tissues-iron chlorosis in calcareous soils. Plant Soil 1994, 165, 275-283. [CrossRef]

8. Tagliavini, M.; Scudellari, D.; Marangoni, B.; Toselli, M. Acid-spray regreening of kiwifruit leaves affected by lime-induced iron chlorosis. In Iron Nutrition in Soils and Plants. Developments in Plant and Soil Sciences; Springer: Dordrecht, The Netherlands, 1995; Volume 59.

9. Zhao, Y.; Sun, M.; Liang, Z.; Li, H.; Yu, F.; Liu, S. Analysis of contrast iron chlorosis tolerance in the pear cv. 'Huangguan' grafted onto pyrus betulifolia and quince A grown in calcareous soils. Sci. Hortic. 2020, 271, 109488. [CrossRef]

10. FAOSTAT. 2020. Available online: http://www.fao.org/faostat/zh/\#data (accessed on 1 January 2021).

11. Jiang, S.; Ou, Q.; Wang, F.; Zhang, Y.; Ma, L.; Zhao, Y. Development and application of pear dwarf stock in China. North. Fruits 2018, 2, 1-3. (In Chinese)

12. Prado, R.M.; Alcántara-Vara, E. Tolerance to iron chlorosis in non-grafted quince seedlings and in pear grafted onto quince plants. J. Soil Sci. Plant Nutr. 2011, 11, 119-128. [CrossRef]

13. Ortiz, P.R.; Meza, B.I.C.; Requena, F.R.G.; Flores, G.M.; Barra, J.D.E. Evaluation of different iron compounds in chlorotic Italian lemon trees (Citrus lemon). Plant Physiol. Bioch. 2007, 45, 330-334. [CrossRef]

14. Lucena, J.J. Fe chelates for remediation of Fe chlorosis in strategy I plants. J. Plant Nutr. 2003, 26, 1969-1984. [CrossRef]

15. Fernández, V.; Río, V.D.; Pumariño, L.; Igartua, E.; Abadía, J.; Abadía, A. Foliar fertilization of peach (Prunus persica (L.) Batsch) with different iron formulations: Effects on re-greening, iron concentration and mineral composition in treated and untreated leaf surfaces. Sci. Hortic. 2008, 117, 241-248. [CrossRef]

16. Fernández, V.; Ebert, G. Foliar iron fertilization: A critical review. J. Plant Nutr. 2005, 28, 2113-2124. [CrossRef]

17. Fernández, V.; Ebert, G.; Winkelmann, G. The use of microbial siderophores for foliar iron application studies. Plant Soil 2005, 272, 245-252. [CrossRef]

18. García-Laviña, P.; Álvarez-Fernández, A.; Abadía, J.; Abadía, A. Foliar applications of acids with and without FeSO to control iron chlorosis in pear. Acta Hort. 2002, 594, 217-222. [CrossRef] 
19. Zhao, M.; Chen, X.; Zhao, Z.; Cai, K.; Wang, Z. Releasing of N, P and K of organic fertilizers and their effects on the contents of available Cu, Zn, Fe and Mn in soil. Chin. J. Eco Agric. 2007, 15, 47-50. (In Chinese)

20. Liu, Y.; Yang, S.; Li, S.; Chen, X.; Chen, F. Growth and development of maize (Zea mays L.) in response to different field water management practices: Resource capture and use efficiency. Agric. For. Meteorol. 2010, 150, 606-613.

21. Shen, P.; Wang, C.; Yu, T.; Wu, Z.; Zheng, Y.; Sun, X.; Zheng, Y.; Sun, X.; Luo, S. Differences in iron nutrition characteristics under no tillage and conventional tillage systems in typical brown soils of main peanut producing areas. J. Nucl. Agric. Sci. 2017, 31, 1818-1826. (In Chinese)

22. Raese, J.T.; Parish, C.L.; Staiff, D.C. Nutrition of apple and pear trees with foliar sprays, trunk injections or soil application of iron compounds. J. Plant Nutr. 1986, 9, 987-999. [CrossRef]

23. Mo, F.; Li, X.; Niu, F.; Zhang, C.; Li, S.; Zhang, L.; Xiong, Y. Alternating small and large ridges with full film mulching increase linseed (Linum usitatissimum L.) productivity and economic benefit in a rainfed semiarid environment. Field Crop. Res. 2018, $219,120-130$.

24. Zhang, P.; Wei, T.; Han, Q.; Ren, X.; Jia, Z. Effects of different film mulching methods on soil water productivity and maize yield in a semiarid area of China. Agric. Water Manag. 2020, 241, 106382. (In Chinese) [CrossRef]

25. Liu, M.; Chai, Z.; Sheng, J.; Ding, K.; He, C. Effect of organic fertilizer on the elements of leaves and the yield, quality of Korla fragrant pear. North Hortic. 2014, 10, 159-163. (In Chinese) [CrossRef]

26. Martínez-Cuenca, M.R.; Legaz, F.; Forner-Giner, M.Á.; Primo-Millo, E.; Iglesias, D.J. Bicarbonate blocks iron translocation from cotyledons inducing iron stress responses in Citrus roots. J. Plant Physiol. 2013, 170, 899-905. [CrossRef]

27. Zheng, S.; Tang, C.; Arakawa, Y.; Masaoka, Y. The responses of red clover (Trifolium pratense L.) to iron deficiency: A root Fe(III) chelate reductase. Plant Sci. 2013, 164, 679-687. [CrossRef]

28. Lucena, J.J.; Hernandez-Apaolaza, L. Iron nutrition in plants: An overview. Plant. Soil 2017, 418, 1-4. [CrossRef]

29. Mortvedt, J.J.; Stevenson, F.J. Organic Matter-Micronutrient Reactions in Soil; SSSA Book Series; Soil Science Society of America Inc.: Madison, WI, USA, 1991.

30. Tang, J.; Xu, J.; Wen, Y.; Tian, C.; Lin, Z.; Zhao, B. Effects of organic fertilizer and inorganic fertilizer on the wheat yields and soil nutrients under long-term fertilization. J. Plant Nutr. Fertil. 2019, 25, 1827-1834. (In Chinese)

31. Manna, M.C.; Swarup, A.; Wanjari, R.H.; Mishra, B.; Shahi, D.K. Long-term fertilization, manure and liming effects on soil organic matter and crop yield. Soil Till. Res. 2007, 94, 397-409. [CrossRef]

32. Masunaga, T.; Marques-Fong, J.D. Strategies for increasing micronutrient availability in soil for plant uptake. In Plant Micronutrient Use Efficiency; Elsevier/Academic Press: San Diego, CA, USA, 2018; pp. 195-208.

33. Zhang, X.; Zhang, D.; Sun, W.; Wang, T. The adaptive mechanism of plants to iron deficiency via iron uptake, transport, and homeostasis. Int. J. Mol. Sci. 2019, 20, 2424. [CrossRef]

34. Huang, J.; Peng, Z.; Wu, X.; Wu, X.; Yu, J.; Liu, H.; Yang, L.; Zhang, Z. Effects of applying amino acids on root active of Chinese cabbage and soil biological activity. Chin. Agric. Sci. Bull. 2014, 30, 108-194. (In Chinese)

35. Jolley, V.D.; Cook, K.A.; Hansen, N.C.; Stevens, W.B. Plant physiological responses for genotypic evaluation of iron efficiency in strategy I and strategy II plants-a review. J. Plant Nutr. 1996, 19, 1241-1255. [CrossRef]

36. Garnica, M.; Bacaicoa, E.; Mora, V.; Francisco, S.S.; Baigorri, R.; Zamarreño, A.M.; Garcia-Mina, J.M. Shoot iron status and auxin are involved in iron deficiency-induced phytosiderophores release in wheat. BMC Plant Biol. 2018, 18, 1471-2229. [CrossRef]

37. Yuan, Y. FIT interacts with AtbHLH38 and AtbHLH39 in regulating iron uptake gene expression for iron homeostasis in Arabidopsis. Cell Res. 2008, 18, 385-402. [CrossRef]

38. En-Jung, H.; Waters, B.M. Alkaline stress and iron deficiency regulate iron uptake and riboflavin synthesis gene expression differently in root and leaf tissue: Implications for iron deficiency chlorosis. J. Exp. Bot. 2016, 67, 5671-5685.

39. Romera, F.J.; Alcantara, E.; Guardia, M.D. Effects of bicarbonate, phosphate and high pH on the reducing capacity of Fe-deficient sunflower and cucumber plants. J. Plant Nutr. 1992, 15, 1519-1530. [CrossRef]

40. White, P.F.; Robson, A.D. Response of lupins (Lupinus angustifolius L.) and peas (Pisum sativum L.) to Fe deficiency induced by low concentrations of $\mathrm{Fe}$ in solution or by addition of $\mathrm{HCO}_{3}{ }^{-}$. Plant Soil 1990, 125, 39-47. [CrossRef]

41. Fleming, A.L.; Chane, R.L.; Coulombe, B.A. Bicarbonate inhibits Fe stress response and Fe uptake translocation of chlorosis susceptible soybeans cultivars. J. Plant Nutr. 1984, 7, 699-714. [CrossRef]

42. Deal, G.M.; Alcantara, E. Bicarbonate and low iron level increase root to total plant weight ratio in olive and peach rootstock. J. Plant Nutr. 2002, 25, 1021-1032.

43. Gharsalli, M.; Zribi, K.; Hajji, M. Physiological responses of pea to iron deficiency induced by bicarbonate. In Plant Nutrition-Food Security and Sustainability of Agro-Ecosystems; Kluwer Academic Publishers: Dordrecht, The Netherlands, 2001 ; pp. 606-607.

44. Zuo, Y.; Ren, L.; Zhang, F.; Jiang, R.F. Bicarbonate concentration as affected by soil water content controls iron nutrition of peanut plants in a calcareous soil. Plant Physiol. Bioch. 2007, 45, 357-364. [CrossRef]

45. Lucena, J.J. Effects of bicarbonate, nitrate and other environmental factors on iron deficiency chlorosis: A review. J. Plant Nutr. 2000, 23, 1591-1606. [CrossRef]

46. Morales, F.; Grasa, R.; Abadía, A.; Abadía, J. Iron chlorosis paradox in fruit trees. J. Plant Nutr. 1998, 21, 815-825. [CrossRef]

47. Abadía, J.; Vázquez, S.; Rellán-Álvarez, R.; El-Jendoubi, H.; Abadía, A.; Álvarez-Fernández, A.; López-Millán, A.F. Towards a knowledge-based correction of iron chlorosis. Plant. Physiol. Bioch. 2011, 49, 471-482. [CrossRef] 
48. Martínez-Cuenca, M.R.; Primo-Capella, A.; Quiñones, A.; Bermejo, A.; Forner-Giner, M.A. Rootstock influence on iron uptake responses in citrus leaves and their regulation under the Fe paradox effect. PeerJ 2017, 5, 3553. [CrossRef]

49. Ding, W.; Clode, P.L.; Lambers, H. Effects of $\mathrm{pH}$ and bicarbonate on the nutrient status and growth of three Lupinus species. Plant Soil 2020, 447, 9-28. [CrossRef]

50. Jassim, M.A.A.; Sukri, H.S.B. Effect of iron and sulfur on leaves nutrient concentrations of dixired peach trees. Int. J. Plant Res. 2020, 10, 27-32.

51. Bityutskii, N.P.; Yakkonen, K.L.; Lukina, K.A.; Semenov, K.N. Fullerenol increases effectiveness of foliar iron fertilization in iron-deficient cucumber. PLoS ONE 2020, 15, e0232765. [CrossRef]

52. Adhikari, R.; Bristow, K.L.; Casey, P.S.; Freischmidt, G.; Hornbuckle, J.W.; Adhikari, B. Preformed and sprayable polymeric mulch film to improve agricultural water use efficiency. Agric. Water Manag. 2016, 169, 1-13. [CrossRef] 